\title{
Economic Performance and Stabilization Policy in a Monetary Union with Imperfect Labor and Goods'
}

\author{
Markets*
}

\author{
Fabrizio Coricelli, Alex Cukierman and Alberto Dalmazzo ${ }^{\dagger}$
}

December, 19, 2000

\begin{abstract}
This paper develops a framework for the analysis of the effects of institutions on economic performance in a monetary union in the presence of stabilization policy, unionized labor markets and monopolistically competitive, price setting firms. Nominal wages are fixed contractually. In spite of full price flexibility transmission of monetary policy operates via both aggregate demand and aggregate supply channels.

The paper relates average, as well as country specific economic performance within the monetary union to country size, number of unions, the degree of product differentiation on product markets, and central bank conservativeness. Economic performance is characterized by unemployment, inflation, real wages and competitiveness. Both average, as well as, country specific, economic performance in the presence of (possibly) heterogeneous shocks and a unified stabilization policy are evaluated.

Keywords: Monetary Union, Central Bank Conservativeness, Shocks, Stabilization Policy, Wage Bargaining, Monopolistic Competition

JEL Classification: E58, E24, E31.
\end{abstract}

\footnotetext{
*Paper presented at the CES-ifo, Yrjo Jahnsson Foundation conference on "Issues of Monetary Integration in Europe", Munich, Germany, December, 1-2, 2000.

${ }^{\dagger}$ Fabrizio Coricelli; University of Siena and CEPR, Alex Cukierman; Tel - Aviv University, and Center for Economic Research, Tilburg University, Alberto Dalmazzo; University of Siena. E-mails: Coricelli: <coricelli@unisi.it>, Cukierman: <alexcuk@ccsg.tau.ac.il>, Dalmazzo: <dalmazzo@unisi.it>.
} 


\section{Introduction}

This paper proposes a framework for the analysis of the effects of institutions on economic performance in a monetary union in the presence of stabilization policy, unionized labor markets and monopolistically competitive, price setting firms. The development of such a framework is motivated by the creation of the European Monetary Union (EMU), by the observation that European labor markets are characterized by high levels of unionization with varying degrees of centralization of wage bargaining across countries within the Monetary Union (MU), and by the belief that the paradigm of monopolistically competitive, price setting firms, provides a more realistic description of reality than that of perfectly competitive firms.

The paper has three main objectives. First to analyze the effects of variations in country size and in the degree of centralization of wage bargaining across countries, on average, as well as on country specific economic performance in the presence of a single unified monetary policy. Second, to analyze the effect of the level of conservativeness of the common central bank on union wide, as well as on country specific, average economic performance. Finally, to examine how those institutional factors (country size, centralization of wage bargaining and central bank conservativeness) are likely to affect stabilization policy by the common central bank (CB) in the face of common, as well as of differential, demand and productivity shocks.

It is, by now, well accepted that the effective level of central bank conservativeness $(\mathrm{CBC})$ is negatively related to inflation. Recent literature has additionally discovered that, in the presence of large wage setters, the level of $\mathrm{CBC}$ also affects real economic activity even if unions are not averse to inflation, and that the magnitude of those real effects depends on the structure of wage bargaining (Cukierman and Lippi (1999a), Soskice and Iversen (2000), Lippi (1999), Coricelli, Cukierman and Dalmazzo (2000)). ${ }^{1}$ Since the countries in the MU differ in size and in the degree of centralization of wage bargaining (CWB) a common monetary policy has differential effects on economic performance in different countries even in the absence of shocks (a recent survey appears in Franzese (2000)). This statement is a fortiori true in the presence

\footnotetext{
${ }^{1}$ Some of the literature has noted that the level of CBC has real effects only when unions are averse to inflation (Yashiv (1989), Gylfason and Lindbeck (1994), Jensen (1997), Skott (1997) and Gruner and Hefeker (1999)). The breakdown of monetary neutrality in this case is not as surprising as in the case in which all individuals in the private sector care only about real variables.
} 
of country specific shocks. The paper provides a framework that makes it possible to analyze these differential impacts of a common monetary policy. ${ }^{2}$

The creation of EMU has raised the level of effective CBC for most countries that have joined the monetary union. When $\mathrm{CBC}$ has real effects one may question whether such a reform of monetary policymaking institutions is a desirable one or not. The paper's framework makes it possible to identify some of the factors that affect the answer to this question. In particular, the paper shows that a higher level of CBC is associated, on average, with both lower inflation and lower unemployment at the level of each country. But in the presence of shocks, which make it desirable to engage in stabilization policy a familiar Rogoff (1985) type tradeoff between better average economic performance and the stabilization of shocks arises.

More generally the paper' framework makes it possible to relate average as well as country specific economic performance in the MU to country size and to structural parameters like the, country specific, degrees of CWB and the level of competition on product markets. In particular it is shown that the higher CWB and the higher product market competitiveness in the MU, the lower the expected values of inflation and of the MU wide rate of unemployment. The paper also shows that, other things the same, countries in the MU that possess relatively more centralized wage bargaining systems are relatively more competitive in foreign trade within the union and enjoy lower rates of unemployment. Similar conclusions hold for relatively larger countries. Basically, those results are a direct consequence of the fact that unions in larger countries with more centralized wage bargaining systems internalize a larger fraction of the impact of their actions on employment, which moderates their wage demands.

The paper shows that, independently of its level of conservativeness, the $\mathrm{CB}$ of the MU fully offsets an appropriately weighted average of the demand shocks impacting individual countries. Although optimal at the level of the entire MU, a policy rule that fully offsets the effects of MU wide demand shocks does not fully stabilize the effect of differential demand shocks on individual countries rates of unemployment. Unlike in the case of demand shocks, the level of $\mathrm{CBC}$ affects the degree of activism in the face of $\mathrm{MU}$ wide productivity shocks. A novel

\footnotetext{
${ }^{2}$ In related work Gruner and Hefeker (1999) and Cukierman and Lippi (1999b) analyze the real effects of the replacement of national monetary policies or an ERM by a monetary union. Those effects are triggered by the change in the strategic interaction between unions and the CB.
} 
result of the paper is that a more conservative CB reacts more strongly to supply shocks in order to better stabilize inflation. This result is consistent with recent time series evidence on conservativenes and activism in Germany presented in Berger and Woitek (1999).

Section 2 presents the basic building blocks of the model and derives its equilibrium solution. The interaction between unions, the CB and firms is specified as a three stage game between (nominal) wage setting unions, a CB that picks the money supply in the MU, and a large number of monopolistically competitive, price setting, firms in the countries within the MU. Section 3 discusses the effects of country size and other institutional parameters, like product market competitivenes, $\mathrm{CWB}$ and $\mathrm{CBC}$ on expected economic performance at the MU and at the individual country level. Section 4 discusses the implications of optimal stabilization of shocks at the level of the MU for CB activism and the actual values of inflation, MU wide unemployment, country specific rates of unemployment and relative competitiveness. This is followed by concluding remarks.

\section{The model}

The analytical framework is an extension of the closed economy model in Coricelli, Cukierman and Dalmazzo (2000) (Henceforth CCD). The extension explicitly recognizes open economy interactions and the existence of productivity and demand shocks. The monetary union is composed of two countries. In each country there is a a continuum of monopolistically competitive firms each producing a single partially differentiated product. The labor force in each country is divided into equally sized, labor unions that organize the country's entire labor force. The firms of both countries are evenly distributed over the unit interval and their total mass is one. A fraction, $s_{1}$ of firms is located in country 1 and the remainder $\left(s_{2}=1-s_{1}\right)$ is located in country 2 .

Each union in each country organizes a labor pool of size $1 / n_{c}$ where $n_{c}$ is the number of unions in country $c$ and $c=1,2$. As a consequence $s_{c}$ also represents the share of country $c$ in the combined labor force of the monetary union. A quantity $L_{0}$ of workers, equal across firms, is attached to each firm but works only if the union in charge signs a labor contract with the firm. For convenience, and without loss of generality, the firms in country $c$ are indexed so that 
all firms whose labor force is represented by union $i$ are located in the contiguous subinterval $\left(\frac{i}{n_{c}} s_{c}, \frac{i+1}{n_{c}} s_{c}\right)$ of the interval of lenght $s_{c}$ where $i=0,1 \ldots, n_{c}-1$. In both countries each firm owns a production technology that exhibits decreasing returns to scale to labor input and is subject to a, country specific, productivity shock $Z_{c}$ whose logarithm has an expected value of zero.

$$
Y_{i j}^{c}=L_{i j}^{\alpha} \cdot Z_{c}, \quad \alpha<1, c=1,2
$$

Here $Y_{i j}^{c}$ and $L_{i j}^{c}$ are output supply and labor input of firm $j$ in country $c$. The index $i$ means that the labor force of the firm belongs to union $i$. The realizations of productivity shocks may have a common component across countries as well as country specific components. Each firm in country 1 faces a demand for its output given by

$$
D_{i j}^{c}=\left(\frac{P_{i j}}{P}\right)^{-\eta}\left(\frac{M_{1}}{P}\right)^{a_{c}}\left(\frac{M_{2}}{P}\right)^{1-a_{c}} \hat{G_{c}}, \quad \eta>1, \quad c=1,2
$$

where $P_{i j}$ and $P$ are respectively the price charged by the individual firm and the general price level respectively. $M_{c}, c=1,2$ is the amount of nominal money balances possessed by individuals in country $c$, and $\eta$ is the (absolute value of the) elasticity of demand facing the individual firm with respect to its relative price. $G_{c}$ is a, country specific shock to the demands facing firms in country $c$. Equation (2) states that the demand facing the individual firm in country $c$ is increasing in the real money balances of both countries and decreasing in the relative price of its product. ${ }^{3}$ The realizations of demand shocks may have a common component across countries as well as country specific components.

The general price level is defined as the integral, over the unit interval, of the (logaritms of) the prices of individual firms. It is convenient, for reasons that will become clearer later, to write it as

\footnotetext{
${ }^{3}$ The demand function in equation (2) is an open economy extension of the one postulated in Akerlof and Yellen (1985). See also Blanchard and Kiyotaki (1987) and chapter 8 of Blanchard and Fischer (1989).
} 


$$
\begin{aligned}
p & =\frac{s_{1}}{n_{1}} \sum_{i=0}^{n_{1}-1}\left(\frac{\int_{\frac{i}{n_{1}} s_{1}}^{\frac{i+1}{n_{1}} s_{1}} p_{i j}^{1} d j}{\int_{\frac{i+1}{n_{1}} s_{1}}^{\frac{i}{n_{1}}} d j}\right)+\frac{s_{2}}{n_{2}} \sum_{i=0}^{n_{2}-1}\left(\frac{\int_{\frac{i}{n_{2}} s_{2}}^{\frac{i+1}{n_{2}} s_{2}} p_{i j}^{2} d j}{\int_{\frac{i}{n_{2}} s_{2}}^{\frac{i+1}{n_{2}}} d j}\right)= \\
& =\left\{\sum_{i=0}^{n_{1}-1} \int_{\frac{i}{n_{1}} s_{1}}^{\frac{i+1}{n_{1}} s_{1}} p_{i j}^{1} d j+\sum_{i=0}^{n_{2}-1} \int_{\frac{i}{n_{2}} s_{2}}^{\frac{i+1}{n_{2}} s_{2}} p_{i j}^{2} d j\right\} \equiv s_{1} p_{1}+s_{2} p_{2}=\int_{0}^{1} p_{i j} d j .
\end{aligned}
$$

where $p_{i j}^{c}$ is the logarithm of $P_{i j}^{c}, p$ is the logarithm of $P$, and $p_{c}, c=1,2$, is an index of the average level of the (logarithms of) prices of the products of country $c$ (see also equation (11) and (12) below). This way of expressing the general price level facilitates the identification of the firms that are affected by an increase in the nominal wage rate set by union $i$. The general price level is a weighted average of the prices of goods produced in both countries. It is meant to represent the average price of the, assumed identical, consumption basket of a typical individual in both countries. Since individuals in both countries consume all the range of differentiated products produced in both countries the summation of individual prices is over the entire unit interval. Since they have the same consumption basket the relevant general price index is the same for both countries.

The $\mathrm{CB}$ of the MU dislikes both inflation and unemployment. Its loss function is given by

$$
\Gamma=u^{2}+I \pi^{2}
$$

where $u$ and $\pi \equiv p-p_{-1}$ denote respectively the average rate of unemployment and of price inflation in the MU. The parameter $I$ is the (Rogoff (1985) type) degree of CB conservativeness, or weight-conservativeness. ${ }^{4}$ The policy instrument of the CB is the nominal money supply, $M$.

Each union likes a higher real wage, and dislikes unemployment among its members. We abstract from possible inflation-aversion on the part of unions by postulating that the loss function of a typical union is: ${ }^{5}$

\footnotetext{
${ }^{4}$ We shall also occasionally refer to the parameter $I$ as central bank independence (CBI).

${ }^{5}$ In that we deviate from much of the recent literature on the strategic interaction between unions and the CB
} 


$$
\Omega_{i}=-2 w_{r i}+A u_{i}^{2}
$$

where $w_{r i}$ is the (logarithm) of the real wage of union's $i$ members, $u_{i}$ is the rate of unemployment among them and $A$ is a positive parameter that measures the relative importance attributed to employment versus the real wage by the union's leadership. This specification is in the spirit of theories of labor union behavior as surveyed in Oswald (1982). Although the union cares about the real wage, it directly sets only the nominal wage. Prices and the money supply are more flexible than nominal wages which are usually contractually fixed. This wage stickiness leaves some room for the conduct of beneficial stabilization policy by the CB of the MU.

Those presumptions are formalized by assuming that unions choose nominal wages prior to the realization of shocks and that the monetary union's supply of money as well as individual prices in both countries are chosen after the realization of shocks. More precisely, we consider the following three-stage game. In the first stage each union in each country, chooses its nominal wage so as to minimize the expected value of its loss function. In doing that each union takes the nominal wages of other unions as given, forms forecasts of future productivity and demand shocks, and anticipates the reactions of the monetary authority and of firms to its nominal wage choice. The resulting nominal wages are then contractually fixed for the duration of the game. Essentially each union in either country plays Nash against all other unions and acts as a Stackelberg leader with respect to the CB and the firms that are attached to it.

Subsequently to that shocks realize, the monetary authority observes them, and chooses the nominal stock of money in the MU so as to minimize its loss function. In doing that, it takes the preset nominal wages in both countries as given and anticipates the pricing reaction of firms to those wages, to the realizations of the shocks, and to its choice of money supply. The monetary authority can change the total money supply in the union but it cannot taylor the levels of monetary injections differentially in line with the differences in shock realizations

which assumes that unions are averse to inflation. A non exhaustive list includes Jensen (1997), Skott (1997), Cukierman and Lippi (1999a), Guzzo and Velasco (1999), Lippi (2000), Lawler (2000) and our own work in Coricelli, Cukierman and Dalmazzo (2000). The reason for this abstraction is based on the belief that the fears of unions from unemployment among their members are far more important in their strategic interaction with the CB than their fears from inflation. 
between countries. In particular we assume that the total money supply in the MU is always distributed across countries in proportion to the relative size of the countries. Thus

$$
M_{c}=s_{c} M, \quad c=1,2 .
$$

In the last stage each firm takes the general price level as given and sets its own price so as to maximize its real profits. The resulting string of first order conditions, along with equation (3), simultaneously determine individual prices as well as the general price level. General equilibrium is characterized by solving the game using backward induction.

\subsection{Price setting}

Inserting equation (6) into equation (2), demand facing a typical firm in the MU can be rewritten as:

$$
D_{i j}^{c}=\left(\frac{P_{i j}}{P}\right)^{-\eta}\left(\frac{M}{P}\right) G_{c}, \quad c=1,2
$$

where $G_{c} \equiv \hat{G}_{c} s_{1}^{a_{c}} s_{2}^{1-a_{c}}, c=1,2$. The distributions of $\hat{G}_{1}$ and of $\hat{G}_{2}$ are chosen so that the expected values of the logarithms of $G_{1}$ and of $G_{2}$ are both zero.

In the last stage, after the realizations of shocks in the MU, each firm observes the level of demand for its own product and sets its price so as to maximize profits. Using equations (1) and (7), real profits of an individual firm in country $c$ are given by

$$
\Pi_{i j}^{c}=\frac{P_{i j}}{P} Y_{i j}^{d}-\frac{W_{i}}{P} L_{i j}=\left(\frac{P_{i j}}{P}\right)^{1-\eta} \frac{M}{P} G_{c}-\frac{W_{i}}{P}\left[\left(\frac{P_{i j}}{P}\right)^{-\eta} \frac{M}{P} \frac{G_{c}}{Z_{c}}\right]^{\frac{1}{\alpha}}
$$

When it chooses its own price, $P_{i j}$, the firm knows the values of the shocks that have realized 
and takes them, along with $P, M$ and the nominal wage, $W_{i}$, as given. ${ }^{6}$ Maximizing profits with respect to $P_{i j}$, taking logarithms of both sides of the resulting expression and rearranging yields the following solution for the relative price of firm " $i j$ " in country $c$

$$
p_{i j}^{c}-p=\theta+\frac{1}{\alpha+\eta(1-\alpha)}\left[\alpha\left(w_{i}^{c}-p\right)+(1-\alpha)\left(m-p+g_{c}\right)-z_{c}\right], \quad c=1,2
$$

Here $\theta \equiv\left[\frac{\alpha}{\alpha+\eta(1-\alpha)}\right] \log \left[\frac{\eta}{\alpha(\eta-1)}\right]$ and lower case letters stand for the logarithms of the corresponding upper case letters. In particular, $\log \left(Z_{c}\right) \equiv z_{c}$, where $z_{c}$ is a random shock with $E\left(z_{c}\right)=0$ and $E\left(z_{c}^{2}\right)=\sigma_{z c}^{2} ;$ similarly, $\log \left(G_{c}\right) \equiv g_{c}$, where $g_{c}$ is a random shock with $E\left(g_{c}\right)=0$, $E\left(g_{c}^{2}\right)=\sigma_{g c}^{2}, c=1,2$. Equation (8) states that the optimal relative price of a typical monopolistically competitive firm is higher, $(i)$ the higher is the real wage relative to the productivity shock, and (ii) the higher real money balances in the MU. The first element reflects the firm's reaction to labor costs and the second its reaction to the demand for its product. The firm's derived demand for labor can be obtained by equating the product demand (equation (2a)) with the firm's supply (equation (1)). Taking logarithms of both sides of the resulting expression and rearranging

$$
l_{i j}^{d c}=\frac{1}{\alpha}\left[-\eta\left(p_{i j}-p\right)+(m-p)+g_{c}-z_{c}\right], \quad c=1,2 .
$$

Equation (9) states that the individual firm's derived demand for labor is an increasing function of real money balances and a decreasing function of its relative price. From equation (8) the relative price of the firm depends on the real wage it faces. Using (8) in equation (9) we obtain the following alternative form of a typical firm's demand for labor

$$
l_{i j}^{d c}=\kappa+\frac{1}{\alpha+\eta(1-\alpha)}\left[-\eta\left(w_{i}^{c}-p\right)+(m-p)+g_{c}+(\eta-1) z_{c}\right]
$$

\footnotetext{
${ }^{6}$ The index " $j$ " identifies the firm and the index " $i$ " identifies the union that organizes that firm's labor force.
} 
where $\kappa \equiv-\frac{\eta \theta}{\alpha}$. This alternative form implies that, other things the same, when the union manages to raise its real wage, the demand for labor by the firm goes down unless real money balances also increase. This completes the analysis of firm $j$ 's optimal decision in the last stage of the game.

\subsection{Choice of money supply by the CB}

In the second stage of the game the $\mathrm{CB}$ of the MU chooses the money supply after the realization of all shocks in the union. The CB sets the money supply so as to minimize its loss function in equation (4) taking the nominal wages set by labor unions as given, and anticipating the pricing and employment reaction of firms to its choice (as given by equations (8) through (10)). The general price level in equation (3) can be rewritten as

$$
p=s_{1} p_{1}+s_{2} p_{2}
$$

where

$$
p_{1} \equiv \frac{\int_{0}^{s_{1}} p_{i j}^{1} d j}{s_{1}} \text { and } p_{2} \equiv \frac{\int_{s_{1}}^{1} p_{i j}^{2} d j}{s_{2}}
$$

The indices $p_{1}$ and $p_{2}$ represent the average price levels of the goods produced by the firms in country 1 and country 2 respectively. Averaging equation (8) over firms within each country and rearranging, we obtain

$$
\begin{aligned}
s_{2}\left(p_{1}-p_{2}\right) & =\theta+\frac{1}{\alpha+\eta(1-\alpha)}\left[\alpha\left(w_{1}-p\right)+(1-\alpha)\left(m-p+g_{1}\right)-z_{1}\right] \\
-s_{1}\left(p_{1}-p_{2}\right) & =\theta+\frac{1}{\alpha+\eta(1-\alpha)}\left[\alpha\left(w_{2}-p\right)+(1-\alpha)\left(m-p+g_{2}\right)-z_{2}\right]
\end{aligned}
$$

where $w_{c}$ is the average nominal wage in country $c .^{7}$ Equations (11) through (13) determine

\footnotetext{
${ }^{7}$ More precisely, it is an average of the logarithms of nominal wages in country $c$.
} 
the general price level, $p$, and its national components, $p_{1}$ and $p_{2}$ as functions of the shocks, the average nominal wages in the two countries, and the money supply of the MU. The solution that emerges for the general price level is, after some algebra, given by

$$
p=[\alpha+\eta(1-\alpha)] \theta+\alpha \bar{w}+(1-\alpha)(m+\bar{g})-\bar{z}
$$

The rate of inflation is, therefore,

$$
\pi \equiv p-p_{-1}=[\alpha+\eta(1-\alpha)] \theta+\alpha \bar{w}+(1-\alpha)(m+\bar{g})-\bar{z}-p_{-1}
$$

where

$$
\bar{w} \equiv s_{1} w_{1}+s_{2} w_{2}, \quad \bar{g} \equiv s_{1} g_{1}+s_{2} g_{2}, \quad \bar{z} \equiv s_{1} z_{1}+s_{2} z_{2}
$$

We now turn to a characterization of unemployment. Averaging equation (9) over firms within a given country yields the average level of demand for labor, and employment, per firm:

$$
l_{c}^{d}=\frac{1}{\alpha}\left[-\eta\left(p_{c}-p\right)+(m-p)+g_{c}-z_{c}\right], \quad c=1,2 .
$$

Let $l_{0} \equiv \log \left[L_{0}\right]$ be the logarithm of labor supply per firm. The average rate of unemployment per firm, as well as the average country specific rates of unemployment are given by

$$
u_{c}=l_{0}-l_{c}^{d}=l_{0}+\frac{1}{\alpha}\left[\eta\left(p_{c}-p\right)-(m-p)+z_{c}-g_{c}\right], \quad c=1,2 .
$$

Thus, the rate of unemployment in country $c$ is higher the higher are the average relative price of the products of that country and the higher the realization of the country's productivity shock. 
It is lower, the higher the level of real money balances in the MU and the higher is the realization of demand for the products of the country. The positive association between productivity and unemployment reflects the fact that, given the average relative price of the products of a country, the demand for the labor of this country is lower the more productive is labor. ${ }^{8}$ Let $L_{c}$ and $L_{c}^{d}$ be total labor supply and total labor demand in country $c$. Unemployment in the monetary union is therefore

$$
u=\frac{L_{1}-L_{1}^{d}+L_{2}-L_{2}^{d}}{L_{1}+L_{2}}=\frac{L_{1}}{L_{1}+L_{2}} \frac{L_{1}-L_{1}^{d}}{L_{1}}+\frac{L_{2}}{L_{1}+L_{2}} \frac{L_{2}-L_{2}^{d}}{L_{2}}=s_{1} u_{1}+s_{2} u_{2} .
$$

Substituting equations (17) into equation (18), using equation (14) and rearranging

$$
u=l_{0}+\frac{\alpha+\eta(1-\alpha)}{\alpha} \theta+\bar{w}-m-\bar{g}
$$

Taking the average nominal wage in the MU as given, the CB chooses the nominal stock of money $m$ so as to minimize its loss function. Substituting the expressions for inflation and unemployment (equations (15) and (19)) into equation (4) and rearranging terms, the CB problem becomes

$$
\min _{\{m\}}\left\{\begin{array}{c}
{\left[l_{0}+\frac{\alpha+\eta(1-\alpha)}{\alpha} \theta+\bar{w}-m-\bar{g}\right]^{2}+} \\
+I\left[(\alpha+\eta(1-\alpha)) \theta+\alpha \bar{w}+(1-\alpha)(m+\bar{g})-\bar{z}-p_{-1}\right]^{2}
\end{array}\right\}
$$

This yields a reaction function for the $\mathrm{CB}$ in which the money supply is a linear function of the average nominal wage, $\bar{w}$, in the $\mathrm{MU}$ and of the average, $\mathrm{MU}$ wide realizations, of the productivity and demand shocks $\bar{z}$ and of $\bar{g}$ :

\footnotetext{
${ }^{8}$ But a higher productivity level also raises the competitiveness of a country's products $\left(p_{c}-p\right.$ goes down $)$ which reduces unemployment by raising demand for the products of the country. This general equilibrium effect is incorporated into the analysis later.
} 


$$
m=\frac{l_{0}+(1-\alpha(1-\alpha) I) \frac{\alpha+\eta(1-\alpha)}{\alpha} \theta+(1-\alpha) I p_{-1}}{1+(1-\alpha)^{2} I}+\frac{1-\alpha(1-\alpha) I}{1+(1-\alpha)^{2} I} \bar{w}+\frac{(1-\alpha) I}{1+(1-\alpha)^{2} I} \bar{z}-\bar{g}
$$

This reaction function has a number of notable features. First, the CB either counteracts or accommodates an increase in average, union wide, nominal wages depending on the degree of $\mathrm{CB}$ conservativeness (or independence), $I$. If the $\mathrm{CB}$ is sufficiently conservative, in the sense that $1-\alpha(1-\alpha) I<0$, a wage-increase triggers a tightening of the money supply. This result is an extension of a similar result from the closed economy framework in CCD to the case of a MU composed of interdependent open economies. Evidence surveyed in CCD supports the view that, the highly conservative Bundesbank often tightened monetary policy in response to what it considered to be "excessive" wage settlements. ${ }^{9}$ The discussion of the intuition underlying the response of the $\mathrm{CB}$ to the productivity and demand shocks is left to section 4 on stabilization policy.

\subsection{Choice of wages by unions}

In the first stage of the game, prior to the realization of shocks in the MU, each union takes nominal wages set by other unions in the MU as given and chooses its own nominal wage so as to minimize its expected losses from unemployment and a low real wage. Thus, the typical union $i$ minimizes $E\left(\Omega_{i}\right)$, where $\Omega_{i}$ is given by equation (5), and where the expectation is taken over the distribution of shocks in the MU. In doing that, each union takes into consideration the consequences of its wage policy for the prices that will subsequently be set by firms, as well as the expected response of the $\mathrm{CB}$ in equation (21).

Let $w_{i}$ and $w_{-i}$ be respectively the nominal wage of union $i$ and the average nominal wage of all other labor unions in the MU. Taking $w_{-i}$ as given, union $i$ sets a common wage, $w_{i}$, for all its members, which are all the workers attached to firms in the interval $\left[\frac{i}{n_{c}} s_{c}, \frac{i+1}{n_{c}} s_{c}\right], c=1,2$. In the firms represented by union $i$, the relevant average rate of unemployment per firm is given

\footnotetext{
${ }^{9}$ Econometric evidence appears in Cukierman, Rodriguez and Webb (1998) and casual evidence in Hall (1994) and in Hall and Franzese (1998). Further details appear in subsection 2.2 of CCD.
} 
by the difference between the number of workers attached to each firm and the average labor demand for a firm represented by union $i$ :

$$
u_{i}^{c}=l_{0}-\left\{\frac{\int_{\frac{i}{n_{c}} s_{c}}^{\frac{i+1}{n_{c}}} l_{i j}^{d} d j}{\int_{\frac{i}{n_{c}} s_{c}}^{\frac{i+1}{n_{c}} s_{c}} d j}\right\}=l_{0}-l_{i j}^{d c}, \quad i \in c, \quad c=1,2
$$

From equation (10), labor demand, $l_{i j}^{d c}$, of firm $j$, in country $c$, in the interval $\left[\frac{i}{n_{c}} s_{c}, \frac{i+1}{n_{c}} s_{c}\right]$ is a function of aggregate real money balances, the country specific productivity and demand shocks and of the firm's relative price. Since all firms in the interval $\left[\frac{i}{n_{c}} s_{c}, \frac{i+1}{n_{c}} s_{c}\right]$ face the same nominal wage $w_{i}^{c}$, equation (9) implies that $p_{i j}^{c}=p_{i}^{c}$ for all $j \in\left[\frac{i}{n_{c}} s_{c}, \frac{i+1}{n_{c}} s_{c}\right]$. Consequently, union $i$ anticipates that all the firms employing its members will react to the common wage level by setting the same relative price for their products. This consideration in conjunction with equation (10) imply that equation (22) can be rewritten as:

$$
u_{i}^{c}=l_{0}+\frac{1}{\alpha}\left[\eta\left(p_{i}^{c}-p\right)-(m-p)+z_{c}-g_{c}\right], \quad i \in c, \quad c=1,2
$$

Note that the unemployment rate among the members of union $i$ 's is also equal to $u_{i}^{c}$. By minimizing the union's expected loss function

$$
E\left(\Omega_{i}\right)=E\left\{-2\left(w_{i}^{c}-p\right)+A u_{i}^{2}\right\}, \quad i \in c, \quad c=1,2
$$

with respect to the nominal wage, $w_{i}^{c}$, one obtains the following family of first order conditions

$$
E\left\{-\left[1-\frac{d p}{d w_{i}^{c}}\right]+A u_{i}^{c} \frac{d u_{i}^{c}}{d w_{i}^{c}}\right\}=0, \quad i \in c, \quad c=1,2
$$

Equation (24) illustrates the tradeoffs facing the individual union. When it raises its nominal wage by one unit the union takes into consideration that, due to the pricing response of 
firms and of the policy response of the $\mathrm{CB}$, the increase in its real wage is going to be somewhat smaller because the CB does not, generally, fully offset the inflationary consequences of wage push. Hence the effectiveness of an increase in the nominal wage in raising the real wage is less than full. This consideration is captured by the first term in equation (24). In addition, the increase in the nominal wage, by raising the labor costs of firms that use the labor of union $i$,induces those firms to raise their relative price. This reduces the demand for the products of those firms, and their derived demands for the work force of union $i$. As a consequence unemployment among members of union $i$ goes up. This consideration is captured by the second term in equation (24). The upshot is that the optimization problem of the individual labor union involves balancing the benefit of a higher real wage against the cost of a higher rate of unemployment among its members.

Equation (24) provides a string of $n=n_{1}+n_{2}$ equations from which the nominal wages of the $n$ unions in the MU can be solved. A first step towards the solution of this system involves the characterization of the effects of an increase in the nominal wage, $w_{i}^{c}$, of the union on the general price level, $p$, and on the rate of unemployment, $u_{i}^{c}$, among the members of the union. Differentiating equation (14) with respect to $w_{i}^{c}$

$$
\frac{d p}{d w_{i}^{c}}=\alpha \frac{s_{c}}{n_{c}}+(1-\alpha) \frac{d m}{d w_{i}^{c}} \quad i \in c, \quad c=1,2 .
$$

To get the impact of an increase in the union's nominal wage rate on the choice of money supply by the CB of the MU we differentiate equation (21) with respect to $w_{i}^{c}$. Substituting the resulting expression into equation (25) and rearranging

$$
\frac{d p}{d w_{i}^{c}}=\frac{s_{c}}{n_{c}}\left(\frac{1}{1+\alpha(1-\alpha)^{2} I}\right), \quad i \in c, \quad c=1,2 .
$$

Note that this expression is smaller than 1 and that it is increasing in country size and decreasing in the number of unions in that country. The intuition is obvious. Since the CB of the MU responds to MU wide aggregates the effect of the nominal wage decisions of a particular union in 
a particular country on the reaction of the CB is smaller the smaller the country of that union, and the larger the number of unions in it. We turn next to a calculation of the impact of the union's wage choice on unemployment among its members. Differentiating equation (23) with respect to $w_{i}^{c}$

$$
\frac{d u_{i}^{c}}{d w_{i}^{c}}=\frac{1}{\alpha}\left[\eta \frac{d\left(p_{i}^{c}-p\right)}{d w_{i}^{c}}-\frac{d(m-p)}{d w_{i}^{c}}\right], \quad i \in c, \quad c=1,2
$$

It is shown in the first part of the appendix that real money balances in the MU are given by

$$
m-p=-\frac{[\alpha+\eta(1-\alpha)] \theta}{1-\alpha}-\frac{\alpha}{1-\alpha}(\bar{w}-p)-\bar{g}+\frac{\bar{z}}{1-\alpha}
$$

Differentiating equation (27) with respect to $w_{i}^{c}$, using equation (25a), and rearranging

$$
\frac{d(m-p)}{d w_{i}^{c}}=-\frac{s_{c}}{n_{c}}\left(\frac{\alpha(1-\alpha) I}{1+\alpha(1-\alpha)^{2} I}\right), \quad i \in c, \quad c=1,2
$$

Thus, an increase in the nominal wage of union $i$ induces a decrease in aggregate real money balances in the MU. This is due to the fact that, although the CB of the MU allows some of the inflationary impact of the wage increase to be passed on in the form of higher prices, it does not fully compensate for the consequent reduction in real money balances. As a consequence aggregate real money balances go down. Not surprisingly, this effect is smaller, the smaller the country of the labor union in question, and the the larger the number of unions in this country. Note also that, the higher the level of CB conservativeness, $I$, the larger the consequent reduction in real money balances.

Differentiating equation (8) with respect to $w_{i}^{c}$, and recalling that all the firms using the labor of union $i$ set the same price, we obtain 


$$
\frac{d\left(p_{i}^{c}-p\right)}{d w_{i}^{c}}=\frac{1}{\alpha+\eta(1-\alpha)}\left[\alpha\left(1-\frac{d p}{d w_{i}^{c}}\right)+(1-\alpha) \frac{d(m-p)}{d w_{i}^{c}}\right], \quad i \in c, \quad c=1,2 .
$$

Substituting equations (28) and (29) into equation (26) and rearranging

$$
\frac{d u_{i}^{c}}{d w_{i}^{c}}=\frac{\eta}{\alpha+\eta(1-\alpha)}\left(1-\frac{s_{c}}{n_{c}}\right)+\frac{s_{c}}{n_{c}} \frac{(1-\alpha) I}{1+\alpha(1-\alpha)^{2} I} \equiv Q_{u}^{c}, \quad i \in c, \quad c=1,2 .
$$

Equation (30) shows that the marginal impact of an increase in the nominal wage of a union on the rate of unemployment among its members is positive and is the same for all unions within a given country. Furthermore, it does not depend on the realizations of shocks in the $\mathrm{MU}$, and it is uniformly larger the higher the degree of competitiveness on product markets (the higher $\eta$ ), and the higher the level of CB conservativeness. Using equation (25a) the marginal impact of an increase in the nominal wage of the union on its real wage is given by:

$$
1-\frac{d p}{d w_{i}^{c}}=1-\frac{s_{c}}{n_{c}}\left(\frac{1}{1+\alpha(1-\alpha)^{2} I}\right) \equiv Q_{w}^{c}, \quad i \in c, \quad c=1,2
$$

Equation (31) is the elasticity of the real wage of a union with respect to the union's nominal wage. The expression in (31) implies that this elasticity is bounded between zero and one, and that it does not depend on the realizations of shocks in the MU. Furthermore, it is larger the larger CB conservativeness, $I$, the smaller the relative size of the country of the union under consideration, and the larger the number of unions in that country. Since the marginal impacts of $w_{i}^{c}$ on the real wage of a union and on its unemployment do not depend on the realizations of shocks in the MU

$$
E\left[1-\frac{d p}{d w_{i}^{c}}\right]=1-\frac{d p}{d w_{i}^{c}}, \quad E\left[\frac{d u_{i}^{c}}{d w_{i}^{c}}\right]=\frac{d u_{i}^{c}}{d w_{i}^{c}}, \quad i \in c, \quad c=1,2
$$

Using equation (32) in equation (24) implies 


$$
-Q_{w}^{c}+A Q_{u}^{c} E u_{i}^{c} \equiv-\left[1-\frac{d p}{d w_{i}^{c}}\right]+A \frac{d u_{i}^{c}}{d w_{i}^{c}} E u_{i}^{c}=0, \quad i \in c, \quad c=1,2
$$

We look for a symmetric equilibrium for nominal wages within each country while allowing differences in nominal and in real wages across countries. The differences in nominal, and therefore also in real wages, across countries reflect, as demonstrated later, differences in country sizes and in the degrees of CWB. It is shown in part 2 of the appendix that in a symmetric equilibrium within each country

$$
\begin{aligned}
& E u^{1}=l_{0}+\frac{((1-\alpha) \eta+\alpha) \theta}{\alpha(1-\alpha)}+\frac{\left((1-\alpha) \eta+\alpha s_{1}\right) E w_{r}^{1}+\alpha s_{2} E w_{r}^{2}}{(1-\alpha)(\alpha+(1-\alpha) \eta)} \\
& E u^{2}=l_{0}+\frac{((1-\alpha) \eta+\alpha) \theta}{\alpha(1-\alpha)}+\frac{\left((1-\alpha) \eta+\alpha s_{2}\right) E w_{r}^{2}+\alpha s_{1} E w_{r}^{1}}{(1-\alpha)(\alpha+(1-\alpha) \eta)}
\end{aligned}
$$

where $E w_{r}^{c}$ is the expected value, prior to the realization of shocks in the MU, of the real wage in country $c$. For reasons that will become apparent in a little while it is convenient to find the (expected value of the) competitive real wage in each country. The system of equations in (33) yields the competitive real wages in the two countries when the expected excess supply of labor in each country is zero. Setting $E u^{1}=E u^{2}=0$ in (33) and rearranging

$$
\begin{aligned}
\left((1-\alpha) \eta+\alpha s_{1}\right) E w_{r c}^{1}+\alpha s_{2} E w_{r c}^{2} & =-(1-\alpha)(\alpha+(1-\alpha) \eta)\left\{l_{0}+\frac{((1-\alpha) \eta+\alpha) \theta}{\alpha(1-\alpha)}\right\} \\
\alpha s_{1} E w_{r c}^{1}+\left((1-\alpha) \eta+\alpha s_{2}\right) E w_{r c}^{2} & =-(1-\alpha)(\alpha+(1-\alpha) \eta)\left\{l_{0}+\frac{((1-\alpha) \eta+\alpha) \theta}{\alpha(1-\alpha)}\right\}
\end{aligned}
$$

where $E w_{r c}^{1}$ and $E w_{r c}^{2}$ are the expected values of the competitive real wages in the two countries. Due to the symmetry of the system in (34) the competitive real wages in the two countries are identical. The common solution is given by 


$$
E w_{r c}^{1}=E w_{r c}^{2}=-\left\{(1-\alpha) l_{0}+((1-\alpha) \eta+\alpha) \frac{\theta}{\alpha}\right\} \equiv E w_{r c} .
$$

Substituting equation (33) into the first order condition in equation (24a) (alternatively for $c=1$ and for $c=2$ ) and using the solution for the competitive real wage in (35) yields, after some rearrangement:

$$
\begin{aligned}
\left((1-\alpha) \eta+\alpha s_{1}\right) \phi_{1}+\alpha s_{2} \phi_{2} & =\frac{(1-\alpha)(\alpha+(1-\alpha) \eta)}{A} \frac{Q_{w}^{1}}{Q_{u}^{1}} \\
\alpha s \phi_{1}+\left((1-\alpha) \eta+\alpha s_{2}\right) \phi_{2} & =\frac{(1-\alpha)(\alpha+(1-\alpha) \eta)}{A} \frac{Q_{w}^{2}}{Q_{u}^{2}}
\end{aligned}
$$

where

$$
\phi_{c} \equiv E\left(w_{r}^{c}-w_{r c}\right)=E w_{r}^{c}-E w_{r c}, \quad c=1,2
$$

is the (expected value of the) difference between the equilibrium wage in country $c$ and the competitive real wage rate. Following CCD we refer to $\phi_{c}$ as the "wage premium" in country c. Equations (36) are the (implicit) reaction functions of the two countries to each other (expected values of) real wages. They imply that the real wages in the two countries are strategic substitutes. When the real wage in one country is higher, the real wage chosen by the the other country is lower. The reason is that a higher real wage in, say, country 2 leads to a higher general price level and depresses real money balances in the MU (see equation (27)). As a consequence the level of demand facing firms in country 1 is lower and so are their derived demands for labor. Hence labor unions in country 1 are content with lower expected real wages. Equations (36) provide a system of two simultaneous equations which determine the wage premia in the two countries. The solutions are given by: 


$$
\phi_{c}=\frac{1}{A}\left\{(1-\alpha) \frac{Q_{w}^{c}}{Q_{u}^{c}}+\frac{\alpha s_{\bar{c}}}{\eta}\left(\frac{Q_{w}^{c}}{Q_{u}^{c}}-\frac{Q_{w}^{\bar{c}}}{Q_{u}^{\bar{c}}}\right)\right\}, c=1,2
$$

where the superscript " $\bar{c} "$ means "not $c "$. For example if $c=1, \bar{c}=2$. The explicit expression for $\frac{Q_{u}^{c}}{Q_{u}^{c}}$ is, from (30) and (31)

$$
q^{c} \equiv \frac{Q_{w}^{c}}{Q_{u}^{c}}=\frac{1-\frac{s_{c}}{n_{c}}\left(\frac{1}{1+\alpha(1-\alpha)^{2} I}\right)}{\frac{\eta}{\alpha+\eta(1-\alpha)}\left(1-\frac{s_{c}}{n_{c}}\right)+\frac{s_{c}}{n_{c}} \frac{(1-\alpha) I}{1+\alpha(1-\alpha)^{2} I}}, \quad c=1,2
$$

Note that the wage premia of the two countries differ if and only if $\frac{s 1}{n_{1}} \neq \frac{s 2}{n_{2}}$. In particular, if $\frac{s_{1}}{n_{1}}=\frac{s_{2}}{n_{2}}$ the expected wage premia are the same in both countries.

\section{The effects of country size and of institutions on the expected values of real wages, unemployment and in- flation}

As will become apparent in a little while, the expected average wage premium in the MU is a fundamental determinant of inflation and of unemployment in the MU. The expected average wage premium in the MU is defined as

$$
\phi \equiv s_{1} \phi_{1}+s_{2} \phi_{2}
$$

Substituting equations (38) into equation (40) and rearranging, this expected value can be expressed as:

$$
\phi=\frac{1-\alpha}{A}\left\{s_{1} \frac{Q_{w}^{1}}{Q_{u}^{1}}+s_{2} \frac{Q_{w}^{2}}{Q_{u}^{2}}\right\} \equiv \frac{1-\alpha}{A}\left\{s_{1} q^{1}+s_{2} q^{2}\right\}
$$


It is shown in part 3 of the appendix that the expected value of average unemployment in the $\mathrm{MU}$ is

$$
E u \equiv E\left(s_{1} u_{1}+s_{2} u_{2}\right)=\frac{1}{1-\alpha} \phi
$$

Thus the expected value of unemployment in the MU is proportional to the expected value of the average wage premium. We turn next to the calculation of expected inflation. The first order condition for the minimization problem of the monetary authority in equation (20) implies

$$
-u+I(1-\alpha) \pi=0 .
$$

Applying the expected value operator to equation (43) and rearranging

$$
E \pi=\frac{E u}{I(1-\alpha)}=\frac{1}{I(1-\alpha)^{2}} \phi
$$

where the second equality follows from the extreme right hand side of equation (42). Thus the rate of inflation in the $\mathrm{MU}$ is directly related to the wage premium. ${ }^{10}$

\subsection{The effects of competitiveness and of CB conservativeness on MU wide variables}

The larger is the parameter $\eta$ in equation (2) the lower the degree of product differentiation and the higher, therefore the intra, as well as the inter, country, degree of competition on product markets. The following proposition summarizes the effects of $\eta$ on the MU wide wage premium, unemployment and inflation.

\footnotetext{
${ }^{10}$ The expressions for the expected values of average unemployment and inflation in the MU are similar to those obtained in the closed economy model obtained in CCD with country variables replaced by their MU aggregate counterparts. Compare equations (42) and (44) here with equations 24 and 25 in CCD.
} 
Proposition 1 The higher the level of competitiveness on product markets as summarized by the parameter $\eta$, the lower the expected values of the average wage premium, the rate of unemployment, and the rate of inflation in the $M U$.

Proof. : Examination of equation (39) reveals that $q^{c}$ is a decreasing function of $\eta$. It follows, from equation (41), (42) and (44) that the MU wide expected values of the wage premium, the rate of unemployment and inflation are all lower.

The intuition underlying the proposition is simple. The more competitive are product markets, the more elastic is the demand for labor of a typical labor union in the MU and the lower therefore the monopoly power of each individual labor union. As a consequence the wage premia and real wages are lower and unemployment is lower as well. When unemployment is lower the Kydland Prescott (1977), Barro-Gordon (1983) (henceforth KPBG) inflation bias is lower too since the temptation of the $\mathrm{CB}$ of the MU to engage in expansionary monetary policy is more moderate. We turn now to an investigation of the effects of CB conservativeness on expected macroeconomic performance in the MU. The following proposition summarizes the main results

Proposition 2 The more conservative the $C B$ of the $M U$, the lower are the expected values of the average wage premium, the average rate of unemployment, and the rate of inflation in the $M U$.

P roof. Differentiating equation (39) with respect to I and rearranging

$$
\frac{\partial q^{c}}{\partial I}=-\frac{(1-\alpha)\left\{2(1-\alpha)^{2} I+1-\frac{s_{c}}{n_{c}}\right\} \frac{s_{c}}{n_{c}}}{\left[\frac{\eta\left(1+\alpha(1-\alpha)^{2} I\right)}{\alpha+\eta(1-\alpha)}\left(1-\frac{s_{c}}{n_{c}}\right)+(1-\alpha) I \frac{s_{c}}{n_{c}}\right]^{2}}<0, \quad c=1,2 .
$$

Application of this result to equation (41) implies that the expected, $M U$ wide, wage premium is lower, the higher is I. It then follows immediatly from equations (42) and (44) that the expected value of unemployment and of inflation in the $M U$ are lower the higher is $I$.

The intuition underlying the proposition is simple. When the CB of the MU is more conservative it is correctly believed to contract the money supply more strongly (or to expand 
it less vigorously) in response to the inflationary consequences of unions' wage increases. This produces a stronger deterrent on the real wage demands of unions. As a consequence, on average, real wages are lower, employment is higher and the KPBG inflation bias is smaller. The latter is smaller both because of the direct effect of a higher level of conservativeness on expected inflation, as well as because of the moderating influence that a higher level of conservativeness exerts on the MU wide expected wage premium, $\phi$ (see equation (44)). This mechanism is basically identical to that found in the closed economy framework in CCD for the case in which unions are not directly averse to inflation. ${ }^{11}$

Proposition $3 q^{c}$ is a decreasing function of $s_{c}$ and an increasing function of $n_{c}$.

Proof. Let $\tau_{c} \equiv \frac{s_{c}}{n_{c}}$. Differentiating $q^{c}$ with respect to $\tau_{c}$ yields

$$
\frac{\partial q^{c}}{\partial \tau_{c}}=-\frac{\alpha(1-\alpha) I}{\left(Q_{u}^{c}\right)^{2}(\alpha+\eta(1-\alpha))\left(1+\alpha(1-\alpha)^{2} I\right)}<0, \quad c=1,2
$$

It follows from this expression that $q^{c}$ is decreasing in $s_{c}$ and increasing in $n_{c}$.

Proposition 3 has the following immediate implication for the determinants of MU wide variables.

Proposition 4 The expected values of the wage premium, unemployment and inflation in the $M U$ are all higher, on average, the larger the number of unions in the $M U$.

The proof is a direct consequence of proposition 3 in conjunction with equations (41), (42) and (44).

We turn now to an intuitive discussion of the results in the propositions. A basic factor that checks the tendency of unions to raise real wages, and with them the wage premia, is the fears of unions from unemployment among their members. This deterrent works via several channels. First, there is a relative price effect. An increase in the wage of a particular union raises the costs of firms that use the labor of that union and leads those firms to raise their prices, which depresses sales and the derived demand for the union's work force.

\footnotetext{
${ }^{11}$ The model in CCD is more general in that it allows for inflation aversion on the part of unions. In this case, although it raises the deterrent effect on unions via their fears from unemployment, an increase in $\mathrm{CB}$ conservativeness weakens the deterrent effect via unions' aversion to inflation. CCD show that for reasonable relative sizes of unions' aversions to unemployment and to inflation, the first effect dominates.
} 
Then, there are two additional mechanisms that further increase unemployment not only among the members of the union under consideration, but also among the members of other unions. One is related to the fact that an increase in the nominal wage of the single union raises the general price level which, in the absence of a policy response, depresses real money balances and aggregate demand for goods, and therefore for labor as well. The other is related to the expected response of the CB. If the CB is relatively liberal ( $I$ is low) it counteracts much of the contractionary economy wide effects of the increase in the union's nominal wage. But if it is sufficiently conservative ( $I$ is large) it responds by reducing the nominal money supply, which further reduces real balances and the demands for goods and labor. For further discussion of those channels the reader is referred to subsection 3.2 of CCD. Importantly even when the CB is relatively liberal the combined effect, on aggregate and union specific demand for labor, of an increase in a single union's wage is negative.

We turn now to an intuitive discussion of proposition 4 . When the number of labor unions is small each union is larger. Hence each union internalizes the adverse aggregate consequences of its own wage demands for employment to a larger extent. As a consequence the deterrent effect of unions' fears from unemployment is weaker the larger the number of unions in the MU. This is the intuition underlying the proposition . Cukierman and Lippi (1999b) rely on a similar mechanism, in the context of inflation averse labor unions, to argue that the formation of a MU, by raising the number of unions playing against the (single in a MU) CB, will raise unions' wage aggressiveness.

The macroeconomic channels underlying proposition 4 can additionally be seen more sharply by calculating the expected value of real money balances in the MU. Applying the expected value operator to equation (27) and using equations (37) and (40)

$$
E(m-p)=-\frac{[\alpha+\eta(1-\alpha)] \theta}{1-\alpha}-\frac{\alpha}{1-\alpha}\left(\phi+E w_{r c}\right)
$$

which implies that the average level of real money balances in the MU is inversely related to the real wage premium. The intuition underlying proposition 4 can now be stated as follows. The larger the number of unions, the larger the real wage premium, the lower real money balances, 
the lower the aggregate demand for labor and the higher, therefore, the rate of unemployment. The higher unemployment, the stronger the incentive of the CB to expand the money supply so that the KPBG inflation bias is higher.

\subsection{Determinants of country specific average performance}

The following proposition summarizes the effects of country size and of country specific CWB for the expected values of country specific variables.

Proposition 5 (i) The country with a higher ratio, $\frac{s_{c}}{n_{c}}$, has a lower expected wage premium and a lower expected rate of unemployment.

(ii) If the two countries are of equal size the country with a more decentralized wage bargaining system (more unions) has a higher expected real wage premium and a higher expected rate of unemployment.

(iii) If the two countries have the same degrees of centralization of wage bargaining $\left(n_{1}=\right.$ $\left.n_{2}\right)$ the smaller country has a higher expected real wage premium and a higher expected rate of unemployment

Proof. The proof of part (i) is obtained by substituting equation (38) into equations (55) in the appendix. After some algebra this yields

$$
E u^{c}=\frac{q^{c}}{A}, \quad c=1,2
$$

The proof of part (i) is completed, by using proposition 3. Parts (ii) and (iii) are particular cases of part (i).

Part (ii) of the proposition is supported by empirical evidence presented in Nickell (1997), OECD (1997) and Nickell (1999).

Since the competitive real wages are the same in both countries all the statements made about wage premia in the above propositions also apply to actual real wages in both countries. Before turning to a discussion of the intuitive bases for the country specific results it is useful to derive an expression for the level of relative competitiveness between the two countries. It is 
shown in part 4 of the appendix that the relative price of the products produced in country $c$ is given by

$$
p_{c}-p=\frac{s_{\bar{c}}}{\alpha+\eta(1-\alpha)}\left\{\alpha\left(w_{c}-w_{\bar{c}}\right)+(1-\alpha)\left(g_{c}-g_{\bar{c}}\right)-\left(z_{c}-z_{\bar{c}}\right)\right\}, \quad c=1,2 .
$$

The expected value of this expression is

$$
E\left(p_{c}-p\right)=\frac{s_{\bar{c}}}{\alpha+\eta(1-\alpha)} \alpha E\left(w_{c}-w_{\bar{c}}\right)=\frac{s_{\bar{c}}}{\alpha+\eta(1-\alpha)} \alpha\left(\phi_{c}-\phi_{\bar{c}}\right), \quad c=1,2
$$

where the second equality is a direct consequence of equation (37). Equation (49a) shows that the country with a higher wage premium charges a higher price for its products and is therefore less competitive than the country with the lower wage premium. This observation, in conjunction with proposition 3 implies

Proposition 6 (i) If the two countries are of equal size, the country with more decentralized bargaining in the labor market is, on average, less competitive.

(ii) If the two countries have similar degrees of $C W B$ the smaller country is, on average, less competitive.

(ii) More generally, country 1 is more or less competitive than country 2 depending on whether $\frac{s_{1}}{n_{1}}$ is larger or smaller than $\frac{s_{2}}{n_{2}}$.

Propostions 5 and 6 imply that, in spite of the common monetary policy, real wages, unemployment and competitiveness differ across the two countries in the MU even in the absence of shocks. The intuition underlying those results is related to the preceding discussion. In particular, the larger the number of unions in a country and the smaller a country's size, the smaller the extent to which a representative union in that country internalizes the adverse macroeconomic consequences of its wage decisions for employment. As a consequence, the real wage premium, and with it the real wage, are higher the smaller the country, and the more decentralized its wage bargaining process. Since it has higher real wages, such a country will 
also be less competitive in its trade with the other country as claimed in proposition 6 and as illustrated by the extreme right hand side of equation (49a).

The following proposition summarizes the effect of CBC, $I$, on the expected values of the rates of unemployment within each country.

Proposition 7 Other things the same, the higher $C B$ conservativeness, the lower the expected value of unemployment in each country of the $M U$.

Proof. The proof is a direct consequence of equations (45) and (48).

\section{Stabilization policy by the central bank of the mone- tary union and the effects of shocks}

The CB of the MU dislikes variability in both inflation and employment. But since it has only one instrument it, generally, cannot fully offset the effect of all shocks on both types of variabilities. It therefore compromises by choosing the money supply so as to equate the marginal cost of inflation variability to the marginal cost of, MU wide, employment variability. But, as can be seen from equation (21), it is nonetheless optimal for the CB to fully offset the effect of the union wide average demand shock on demand for goods in the MU. The reason is that aggregate demand shocks do not require the CB to choose between inflation variability and employment variability. By fully offseting the effects of velocity and other demand shocks on the economy, the $\mathrm{CB}$ reduces fluctuations in both inflation and unemployment. This intuition is similar to that found in New - Keynesian models of monetary policy of the type recently reviewed by Clarida, Gali and Gertler (1999). But in the case of a MU this implies that demand shocks facing producers in a each single country are not necessarily fully offset unless demand shocks are perfectly correlated across countries.

Equation (21) implies that the CB accomodates the MU wide average productivity shock,

$\bar{z}$. The reason is that the union wide average productivity shock does not affect unemployment but does affect inflation. As a consequence the $\mathrm{CB}$ conducts monetary policy so as to offset the effects of fluctuations in productivity only on inflation. This implies that, in the face of a 
positive (negative) productivity shock the money supply is increased (reduced). ${ }^{12}$

The fact that $\bar{z}$ does not affect aggregate unemployment might seem mysterious at first sight. The reason its impact is nil is that the direct, negative, effect of $\bar{z}$ on employment is exactly offset by the indirect general equilibrium effect of $\bar{z}$ on employment via real money balances. In particular, when $\bar{z}$ increases less labor is needed to produce a given level of output so the demand for labor goes down. On the other hand, the increase in output reduces prices and raises real money balances which stimulates demand for goods and, through it, the derived demand for labor. In the model of this paper those two effects exactly offset each other making union wide unemployment independent of $\bar{z}$. Although this perfect offsetting is not likely to hold in general, the effect of $\bar{z}$ on unemployment is likely to be small in comparison to its effect on inflation making it likely that more conservative central banks will be more activist even in the absence of perfect offsetting of the two opposing effects of $\bar{z}$ on union wide unemployment, as happens to be the case here.

Interestingly, a more independent $\mathrm{CB}$ (in the sense that $I$ is higher) is more activist. It therefore pays a CB that is relatively more sensitive to inflation and to inflation variability to be more activist in order to offset a larger fraction of the effects of productivity shocks on inflation and its variance. ${ }^{13}$ Recent time series evidence for Germany presented in Berger and Woitek (1999) is consistent with this implication. They find that when the Bundesbank Council was dominated by more conservative members monetary policy reacted more strongly to exogenous shocks.

\footnotetext{
${ }^{12}$ A similar conclusion is reached by Lane (1999), which extends the Canzoneri-Henderson model to analyse the conduct of monetary policy in a Currency Union where members are subject to shocks.

${ }^{13}$ From the monetary rule in equation (21), the variance of the money supply turns out to be

$$
V A R(m)=E[m-E(m)]^{2}=\frac{(1-\alpha)^{2} I^{2}}{\left[1+(1-\alpha)^{2} I\right]^{2}} \sigma_{\bar{z}}^{2}+\sigma_{\frac{2}{g}}
$$

Since $\frac{\partial V A R(m)}{\partial I}>0$, the degree of activism in the management of money supply increases in CB conservativeness.
} 


\subsection{The effects of the common stabilization policy on MU wide un- employment and inflation}

To evaluate the effect of shocks on inflation in the presence of a common stabilization policy we substitute equation (21) into equation (15) and rearrange. This yields

$$
\pi=\frac{1}{1+(1-\alpha)^{2} I}\left\{(1-\alpha) l_{0}+\frac{[\alpha+\eta(1-\alpha)] \theta}{\alpha}+\bar{w}-p_{-1}-\bar{z}\right\}
$$

Note that the MU wide aggregate demand shock does not appear in this expression. This confirms that, independently of its level of conservativeness, the CB always fully offsets the effect of the aggregate demand shock on MU wide inflation. But it allows some of the MU wide aggregate supply shock, $\bar{z}$, to affect the rate of inflation. Thus a negative, union wide, supply shock is partly allowed to raise inflation and inflation variability. The more conservative the CB the smaller the pass through coefficient. In the limit, when the CB is extremely conservative, inflation and its variability are largely independent of productivity shocks.

We turn next to the MU wide rate of unemployment. It is shown in part 6 of the appendix that the MU wide rate of unemployment is

$$
u=\frac{1}{1-\alpha}\left\{\phi-\frac{(1-\alpha)^{2} I}{1+(1-\alpha)^{2} I} \bar{z}\right\}
$$

Again, this expression confirms that the effect of the aggregate demand shock on unemployment is fully offset. But productivity shocks are allowed to partly affect the MU wide rate of unemployment. The more liberal the $\mathrm{CB}$ (the lower $I$ ) the smaller the fraction of the MU wide average productivity shock that is allowed to affect the, MU wide, rate of unemployment. In the limit when the CB is populist or ultra liberal ( $I$ tends to 0 ) the effect of $\bar{z}$ on MU unemployment is fully neutralized. ${ }^{14}$ As can be seen from equation (50), in this case, supply shocks are fully passed on to inflation.

\footnotetext{
${ }^{14}$ The terms "populist" and "ultra liberal" to designate a CB with $I=0$ are due respectively to Guzzo and Velasco (1999) and Cukierman and Lippi (1999a).
} 


\subsection{Country specific effects of shocks under a common stabilization policy}

Since the policy of the CB of the MU is geared to the stabilization of a weighted average of the shocks in the monetary union, the country specific shocks are, obviously, not stabilized to the same extent that they would have been under national monetary policies. The remainder of this section focusses on the factors that affect the size of the differential effects of the common stabilization policy in the face of heterogeneous cross country shocks.

\subsubsection{Effects on relative competitiveness within the MU}

Not surprisingly, equation (49) suggests that the level of competitiveness of a country in the $\mathrm{MU}$, as measured by the average relative price of the products of that country, depends on the differences between the demand and productivity shocks of the two countries. Other things the same, the country with a higher relative realization of the productivity shock enjoys a better level of competitiveness (a lower relative price) and the producers of the country experiencing a relatively higher demand shock set relatively higher relative prices. The impact of differential shock realizations has a relatively stronger impact on the relative price of the small country. Furthermore, this impact is lower, the less differentiated are the products in the MU ( $\eta$ is higher) and the larger is the exponent, $\alpha$, of the production function.

\subsubsection{Effects of shocks on country specific rates of unemployment}

It is shown in part 5 of the appendix that

$$
\begin{aligned}
u_{c}= & \frac{\phi_{c}}{1-\alpha}+\frac{\alpha s_{\bar{c}}}{(1-\alpha)(\alpha+\eta(1-\alpha))}\left(\phi_{\bar{c}}-\phi_{c}\right)-\frac{(1-\alpha) I\left(\alpha+\eta(1-\alpha)-s_{\bar{c}}\right)+s_{\bar{c}}(\eta-1)}{[\alpha+\eta(1-\alpha)]\left(1+(1-\alpha)^{2} I\right)} z_{c} \\
& -\frac{s_{\bar{c}}((1-\alpha) I-(\eta-1))}{[\alpha+\eta(1-\alpha)]\left(1+(1-\alpha)^{2} I\right)} z_{\bar{c}}+\frac{s_{\bar{c}}}{\alpha+\eta(1-\alpha)}\left(g_{\bar{c}}-g_{c}\right) .
\end{aligned}
$$

where $c=1,2$. Scrutinization of this expression reveals several interesting interactions. First, in spite of the fact that the $\mathrm{CB}$ fully offsets the MU wide average demand shock, $\bar{g}$, the difference between the demand shocks that impact the two countries does affect the country specific 
rates of unemployment. When the two demand shocks are the same stabilization of demand at the level of the MU also neutralizes any effect of demands shocks on country specific rates of unemployment.

But, other things the same, when the two demand shocks are not perfectly correlated the domestic rate of unemployment is higher when the demand shock facing the other country is larger than the one facing the domestic economy. The reason is that the monetary authority responds to a positive, MU wide demand shock by reducing the money supply. When the realization of demand in the other country is larger, the CB contracts more than what is needed to stabilize the domestic economy, causing an increase in its rate of unemployment. This negative externality is more important when the country is relatively small, and less important when product markets are relatively competitive ( $\eta$ is high). Note that the magnitude of this cross impact is independent of CBC. This is due to the fact that all types of central bankers stabilize the MU wide average demand shock to the same extent.

The own productivity shock affects domestic unemployment via three channels that can be seen more explicitly by refering to equation (17). An increase in domestic productivity directly raises domestic unemployment since less labor is now needed to satisfy a given demand for the country's products. But an increase in domestic productivity also raise the country's competitiveness and raises real money balances in the MU. Those two effects raise the demand for domestic products and reduce domestic unemployment. Equation (52) shows that the last two (indirect) effects, dominate the first (direct)effect. Note that the absolute value of the marginal impact of a domestic productivity shock on domestic unemployment is larger, the larger CBC, I. The reason is that a more conservative $\mathrm{CB}$ accomodates productivity shocks more vigorously which leads to a stronger adjustment of real money balances in the MU to supply shocks.

An increase in foreign productivity, by raising real money balances, reduces domestic unemployment (as we just saw, this effect is stronger, the more conservative is the $\mathrm{CB}$ ). On the other hand, an increase in foreign productivity also reduces the competitiveness of domestically produced products thereby raising domestic unemployment. When the CB of the MU is sufficiently conservative the first effect dominates and an increase in foreign productivity reduces domestic unemployment. More precisely, the coefficient of foreign productivity in equation (52) implies the following: 
Proposition 8 An increase in foreign productivity reduces domestic unemployment if and only if

$$
I>\frac{\eta-1}{1-\alpha}
$$

\subsubsection{A remark on the relative variability of national rates of unemployment in a MU}

Equation (52) provides the ingredients needed to identify some of the factors that affect the relative size of the variances of national rates of unemployment in a MU. Although a full analysis of those factors is beyond the scope of this already lenghty paper it is instructive to quickly look at the extreme case in which the variabilities of national rates of unemployment are dominated by demand shocks. More formally, it can be shown that, when the variance of productivity shocks is zero,

$$
\frac{\operatorname{Var}\left(u_{1}\right)}{\operatorname{Var}\left(u_{2}\right)}=\left(\frac{s_{2}}{s_{1}}\right)^{2} .
$$

This implies that the smaller country experiences wider, demand induced, fluctuations in unemployment. This is a consequence of the fact that the $\mathrm{CB}$ of the MU stabilizes mainly the demand shock of the large country.

\section{Concluding remarks}

Rather than summarize the results of the paper we briefly discuss, and sometime speculate, on the implications of our framework for other issues like the possible effects of the creation of the ECB on macroeconomic performance in the Euro area, the incentives for labor market reform and the optimal level of $\mathrm{CBC}$ in a MU.

As stressed by Cukierman and Lippi (1999b) the creation of a MU (by reducing the relative size of a typical union involved in a strategic interaction with the CB) raises real wages. 
This adverse strategic effect raises inflation and unemployment. On the other hand Gasiorek (2000) claims that the creation of the Euro, by increasing transparency about relative prices across countries within EMU, is likely to raise competition on product markets. The results of this paper imply that an increase in the level of competitiveness on goods' markets should reduce real wages throughout the monetary union, and with them, inflation and unemployment. To the extent that the creation of EMU raises, or will raise, competitiveness on goods'markets there is an effect that may partially or fully offset the adverse strategic effect.

In addition the creation of the EMU did not leave the average level of CBC in the Euro area unaltered. For many countries in the Euro area, the creation of the ECB has raised the level of $\mathrm{CB}$ conservativeness. The results of this paper suggest that this institutional change should reduce unions' real wage demand and with them unemployment and the inflation bias. Although the high level of conservativeness of the ECB may lead to insufficient stabilization of fluctuations in employment, the paper unambiguously establishes that expected average performance with respect to both inflation and unemployment is better under a more conservative CB. ${ }^{15}$ There is thus a familiar Rogoff (1985) type generalized tradeoff between better average performance on both inflation and unemployment and the stablization of employment. ${ }^{16}$ This is likely to lead to a Rogoff type result according to which the optimal level of CBC in a MU should be larger than that of society.

Recent work has looked at the effects of monetary integration on the incentives for labor market reform (Calmfors (1998, 2000), and Sibert (2000)). ${ }^{17}$ In particular, Sibert and Sutherland (2000) find that the incentive for labor market reform that would increase the flexibility of wage response to shocks may or may not be stronger under a MU than under national monetary policies. This paper does not provide a direct answer to this question. But it suggests that, since it devotes relatively less attention to the stabilization of employment, a relatively conservative ECB is more likely to stimulate labor market reform in a direction that would make real wages

\footnotetext{
${ }^{15}$ In related work for a single closed economy with many unions Bratsiotis and Martin (1999) reach a similar conclusion using a framework in which the policy rule of the CB (rather than its objectives) is taken as the primitive. In a model with traded and non traded goods Holden (1999a) shows that the type of monetary regime (exchange rate rule versus a price target) affects the composition of employment across sectors.

${ }^{16}$ This tradeoff is a generalized one since a more conservative CB is associated with better average performance not only with respect to inflation, but also with respect to unemployment.

${ }^{17}$ See also Holden (1999b).
} 
more responsive to the macroeconomic effects of supply shocks. One way to achieve such reduced real wage rigidity is by more coordination among labor unions within EMU. In terms of the model this amounts to an effective reduction in the number of unions. Coordination among unions may arise spontaneously or through some centralized initiative on the part of governments as was the case with income policies during the seventies (Flanagan, Soskice and Ulman (1983)). In the context of EMU such initiative would require coordinated actions on the part of individual governments or on the part of some European Community institutions.

We conclude with two remarks on the transmission mechanism of monetary policy featured in this paper as well as in its predecessor (Coricelli, Cukierman and Dalmazzo (2000)) within the context of recent literature on the transmission mechanism. Recently revived New Keynesian models anchor much of the real effects of monetary policy, and therefore also of the stabilizatory capacity of the $\mathrm{CB}$, on sticky prices and aggregate demand management, rather than on a Friedman - Lucas expectations augmented Phillips relation in which the transmission of monetary policy operates via aggregate supply. Our framework postulates that nominal wages are contractually fixed for some time but allows full price flexibility. Since there is little doubt that most nominal wages are relatively more sticky than prices, such a framework captures an important element of reality.

A related advantage of this framework is that it captures the effects of monetary policy on economic activity through both the aggregate demand channel as well as through the aggregate supply channel. The first channel operates through the effect that monetary expansion has on the demand for goods, and through it on the derived demand for labor and employment. The supply channel of the transmission process also operates in the model since the $\mathrm{CB}$ can react to the realization of shocks that had not been anticipated at the time wage contracts had been struck. Thus, the CB has some limited capacity to stabilize the level of employment also by lowering or raising the expost real wage through the creation of unanticipated inflation. 


\section{Appendix}

\subsection{Derivation of equation (27)}

Multiplying the first equation in (13) by $s_{1}$, the second one by $s_{2}$, and substracting the second equation from the first one we obtain:

$$
0=\theta+\frac{1}{\alpha+\eta(1-\alpha)}[\alpha(\bar{w}-p)+(1-\alpha)(m-p+\bar{g})-\bar{z}]
$$

Equation (27) in the text is obtained by using this expression to solve for $m-p$.

\subsection{Derivation of equations (33)}

Applying the expected value operator to equation (23)

$$
E u_{i}^{c}=l_{0}+\frac{1}{\alpha}\left[\eta E\left(p_{i}^{c}-p\right)-E(m-p)\right], \quad i \in c, \quad c=1,2 .
$$

Applying the expected value operator to equation (13), substituting the resulting expression into (53) and rearranging

$$
E u_{i}^{c}=l_{0}+\frac{\eta \theta}{\alpha}+\frac{\eta}{\alpha+\eta(1-\alpha)} w_{r i}^{c}-\frac{E(m-p)}{\alpha+\eta(1-\alpha)}, \quad i \in c, \quad c=1,2 .
$$

Equations (33) are obtained by substituting the expected value of equation (27) into equation (54), by rearranging, alternatively setting the country index, $c$, to 1 and to 2 and by using the assumption of a symmetric equilibrium within each country.

\subsection{Derivation of equation (42)}

Using the expression for the competitive real wage (equation (35)) it is possible to rewrite equations (33) as 


$$
\begin{aligned}
E u^{1} & =\frac{\left((1-\alpha) \eta+\alpha s_{1}\right) \phi_{1}+\alpha s_{2} \phi_{2}}{(1-\alpha)(\alpha+(1-\alpha) \eta)} \\
E u^{2} & =+\frac{\left((1-\alpha) \eta+\alpha s_{2}\right) \phi_{2}+\alpha s_{1} \phi_{1}}{(1-\alpha)(\alpha+(1-\alpha) \eta)} .
\end{aligned}
$$

Since $s_{1}+s_{2}=1$ those equations can be rewritten after some algebra as

$$
\begin{aligned}
E u^{1} & =\frac{\phi_{1}}{(1-\alpha)}+\frac{\alpha s_{2}\left(\phi_{2}-\phi_{1}\right)}{(1-\alpha)(\alpha+(1-\alpha) \eta)} \\
E u^{2} & =\frac{\phi_{2}}{(1-\alpha)}-\frac{\alpha s_{1}\left(\phi_{2}-\phi_{1}\right)}{(1-\alpha)(\alpha+(1-\alpha) \eta)}
\end{aligned}
$$

Equation (42) in the text is obtained by substituting the last two equations into the first part of (42) and by rearranging.

\subsection{Derivation of equation (49)}

Equation (13) provide a system of two simulataneous equations from which the average price levels of the products produced in the two countries $\left(p_{1}\right.$ and $\left.p_{2}\right)$ can be solved in terms of the nominal wages, the money supply and the realizations of shocks. The solutions are given by

$$
p_{c}=\theta D+\frac{1}{D}\left\{\begin{array}{c}
\left(s_{\bar{c}}+D s_{c}\right)\left[\alpha w_{c}+(1-\alpha)\left(m+g_{c}\right)-z_{c}\right] \\
+s_{\bar{c}}(D-1)\left[\alpha w_{\bar{c}}+(1-\alpha)\left(m+g_{\bar{c}}\right)-z_{\bar{c}}\right]
\end{array}\right\}, c=1,2 .
$$

where $D \equiv \alpha+\eta(1-\alpha)$. Equation (46) in the text is obtained by substracting equation (14) from equation (57) and by rearranging. 


\subsection{Derivation of equation (52)}

Substituting equation (49) for the relative price in country $c(c=1,2)$ into the expression for $u_{c}$ (equation (17)) and rearranging

$$
\begin{aligned}
u_{c}= & \frac{-E w_{r c}}{(1-\alpha)}+ \\
& +\frac{(1-\alpha) \eta+\alpha s_{c}}{[(1-\alpha) \eta+\alpha](1-\alpha)}\left(w_{c}-p\right)+\frac{\alpha s_{\bar{c}}}{[(1-\alpha) \eta+\alpha](1-\alpha)}\left(w_{\bar{c}}-p\right)+ \\
& -\frac{(1-\alpha)(\eta-1)+s_{c}}{[(1-\alpha) \eta+\alpha](1-\alpha)} z_{c}-\frac{s_{\bar{c}}}{[(1-\alpha) \eta+\alpha](1-\alpha)} z_{\bar{c}}+ \\
& +\frac{s_{\bar{c}}}{(1-\alpha) \eta+\alpha}\left(g_{\bar{c}}-g_{c}\right)
\end{aligned}
$$

where $\left(w_{c}-p\right) \equiv w_{r}^{c}$, and $\frac{-E w_{r c}}{(1-\alpha)}=\left[l_{0}+\frac{(1-\alpha) \eta+\alpha}{(1-\alpha)} \frac{\theta}{\alpha}\right]($ see equation $(35)) .{ }^{18}$

The aggregate competitive wage, $w_{r c}$, is obtained by setting $u=0$ in equation (19), and using equation (27) to substitute away for $m$. Thus:

$$
w_{r c}=-\left[(1-\alpha) l_{0}+[(1-\alpha) \eta+\alpha] \frac{\theta}{\alpha}\right]+\bar{z}
$$

Since (from (35) and (59)) $E w_{r c}=w_{r c}-\bar{z}$, country $c$ 's unemployment in (58) can be rewritten as:

$$
\begin{aligned}
u_{c}= & \frac{(1-\alpha) \eta+\alpha s_{c}}{[(1-\alpha) \eta+\alpha](1-\alpha)}\left(w_{r}^{c}-w_{r c}\right)+\frac{\alpha s_{\bar{c}}}{[(1-\alpha) \eta+\alpha](1-\alpha)}\left(w_{r}^{\bar{c}}-w_{r c}\right)+ \\
& -\frac{(\eta-1) s_{\bar{c}}}{(1-\alpha) \eta+\alpha}\left(z_{c}-z_{\bar{c}}\right)+\frac{s_{\bar{c}}}{(1-\alpha) \eta+\alpha}\left(g_{\bar{c}}-g_{c}\right)
\end{aligned}
$$

Thus, $u_{c}$ is a function of the differences between the ex-post values of the actual real wage in each country and the aggregate competitive wage $\left(\left(w_{r}^{c}-w_{r c}\right)\right.$ and $\left(w_{r}^{\bar{c}}-w_{r c}\right)$ respectively). Since, by definition, $w_{r}^{c} \equiv w^{c}-p$, the randomness associated with the real wage of each country depends entirely on the realization of the aggregate price level, $p$, in stage 3 . Using equation

\footnotetext{
${ }^{18}$ Note that $w_{c}$ designates the nominal wage in country $c, w_{r c}$ designates the MU wide competitive real wage and $w_{r}^{c}$ designates the competitive real wage in country $c$.
} 
(14):

$$
w_{r}^{c} \equiv w^{c}-p=w^{c}-[((1-\alpha) \eta+\alpha) \theta+\alpha \bar{w}+(1-\alpha)(m+\bar{g})-\bar{z}]
$$

Using equation (21) to substitute $m$ away in (61), the expression for $w_{r}^{c}$ in this equation can be rewritten as:

$$
w_{r}^{c}=E\left(w_{r}^{c}\right)+\frac{1}{1+(1-\alpha)^{2} I} \bar{z}, \quad c=1,2
$$

where $E\left(w_{r}^{c}\right)$ is the expected real wage in country $c$. Combining the expression for $E\left(w_{r c}\right)$ from equation (35) with equation (62) we obtain

$$
w_{r}^{c}-w_{r c}=\left(E\left(w_{r}^{c}\right)+\frac{1}{1+(1-\alpha)^{2} I} \bar{z}\right)-\left(E\left(w_{r c}\right)+\bar{z}\right)=\phi_{c}-\left(\frac{(1-\alpha)^{2} I}{1+(1-\alpha)^{2} I}\right) \bar{z}, c=1,2
$$

Using (63) to substitute away both $\left(w_{r}^{c}-w_{r c}\right)$ and $\left(w_{r}^{\bar{c}}-w_{r c}\right)$ in equation (60) and rearranging, we obtain:

$$
\begin{aligned}
u_{c}= & \left\{\frac{(1-\alpha) \eta+\alpha s_{c}}{[(1-\alpha) \eta+\alpha](1-\alpha)} \phi_{c}+\frac{\alpha s_{\bar{c}}}{[(1-\alpha) \eta+\alpha](1-\alpha)} \phi_{\bar{c}}\right\}+ \\
& -\left[\frac{(1-\alpha) I s_{c}}{1+(1-\alpha)^{2} I}+\frac{(\eta-1) s_{\bar{c}}}{(1-\alpha) \eta+\alpha}\right] \cdot z_{c}-\left[\frac{(1-\alpha) I s_{\bar{c}}}{1+(1-\alpha)^{2} I}-\frac{(\eta-1) s_{\bar{c}}}{(1-\alpha) \eta+\alpha}\right] \cdot z_{\bar{c}}+ \\
& +\frac{s_{\bar{c}}}{(1-\alpha) \eta+\alpha}\left(g_{\bar{c}}-g_{c}\right), \quad c=1,2 .
\end{aligned}
$$

Equation (52) in the text is obtained by rearranging equation (64).

Note that although the aggregate shock $\bar{g}=s_{1} g_{1}+s_{2} g_{2}$ is fully offset by the CB (see equation (21)), the individual shocks $g_{1}$ and $g_{2}$ generally affect each country's individual rates of unemployment.

\subsection{Derivation of equation (51)}

Equation (51) in the text is obtained by substituting equation (64) for $c=1,2$ into equation (18), and by rearranging. 


\section{References}

Barro R. J. and Gordon R. (1983), "A Positive Theory of Monetary Policy in a Natural Rate Model", Journal of Political Economy, 91, 589-610.

Berger H. and U. Woitek (1999), "Does Conservatism Matter? A Time Series Approach to Central Banking", Working Paper No. 190, CES ifo, June.

Blanchard O. and N. Kiyotaki (1987), Monopolistic Competition and the Effects of Aggregate Demand", American Economic Review, 77, September, 647-666.

Blanchard O. and S. Fischer (1989), Lectures in Macroeconomics, The MIT Press, Cambridge, MA.

Bratsiotis G. and C. Martin (1999), "Stabilization, Policy Targets and Unemployment in Imperfectly Competitive Economies", Scandinavian Journal of Economics, 101, 241-256.

Calmfors L. (1998), Monetary Union and Precautionary Labor Market Reform", Seminar Paper No. 659, IIES, Stockholm University, Forthcoming: Journal of Labor Economics.

Calmfors L. (2000), "Unemployment, Labor Market Reform and Monetary Union", Journal of Labor Economics, October.

Calmfors L. (2000), Wages and Wage-Bargaining Institutions in the EMU - A Survey of the Issues", Paper presented at the Austrian National Bank Workshop on: Wage Bargaining Within EMU, October 2000.

Clarida R., J. Gali and M. Gertler, (1999), "The Science of Monetary Policy: A New Keynesian Perspective", Journal of Economic Literature, 37, December, 1661-1707.

Coricelli F., A. Cukierman and A. Dalmazzo (2000), "Monetary Institutions, Monopolistic Competition, Unionized Labor Markets and Economic Performance", CEPR Discussion Paper No. 2407, March. Available on the Web at: http://www.tau.ac.il/ $\sim$ alexcuk/pdf/ccdav3.pdf

Cukierman A.and F. Lippi (1999a), "Central Bank Independence, Centralization of Wage Bargaining, Inflation and Unemployment - Theory and Some Evidence", European Economic Review, 43, 1395-1434. Available on the Web at: http://www.tau.ac.il/ ${ }^{\sim}$ alexcuk/pdf/Lippi1EER.pdf

Cukierman A.and F. Lippi (1999b), "Labour Markets and Monetary Union: A Strategic Analysis", CEPR Discussion Paper No. 2236, September, Forthcoming: Economic Journal. 
Available on the Web at: http://www.tau.ac.il/ alexcuk/pdf/LipiEMU799.pdf

Cukierman A., P. Rodriguez and S. Webb (1998), "Central Bank Autonomy and Exchange Rate Regimes-Their Effects on Monetary Accommodation and Activism", in S. Eijffinger H. Huizinga (eds.), Positive Political Economy-Theory and Evidence, Cambridge University Press, Cambridge, UK and NY.

Flanagan R. J. , D. W. Soskice and L. Ulman (1983) Unionism, Economic Stabilization, and Income Policies: European Experience, The Brookings Institution, Washington, DC.

Franzese R. J. Jr. (2000), "Credibly Conservative Monetary Policy and Wage/Price Bargaining Organization: A Review with Implications for Monetary Policy in the European Common Currency Area", Center for Political Studies, Institute for Social Research, University of Michigan.

Gasiorek M. (2000), "Product Markets and Monetary Union", Paper presented at the CEPR/ESI Conference on Vivent Les Differences? Heterogeneous Europe, Amsterdam, September 2000.

Gruner H. P. and C. Hefeker (1999), "How Will EMU Affect Inflation and Unemployment in Europe?", Scandinavian Journal of Economics, 101, No.1, 33-47.

Guzzo V. and A. Velasco (1999), "The Case for a Populist Central Bank", European Economic Review, 43, 1317-1344.

Gylfason T. and A. Lindbeck (1994), "The Interaction of Monetary Policy and Wages", Public Choice, 79:33-46.

Hall P. A. (1994), "Central Bank Independence and Coordinated Wage Bargaining: Their Interaction in Germany and Europe", German Politics and Society, Issue 31, 1-23.

Hall P. A. and R. J. Franzese Jr. (1998), "Mixed Signals: Central Bank Independence, Coordinated Wage Bargaining, and European Monetary Union", International Organization, $52,3,505-535$.

Holden S. (1999a), "Wage Setting Under Different Monetary Regimes", Memorandum No. 12/99, University of Oslo.

Holden S. (1999b), "Monetary Regimes and the Coordination of Wage Setting", Manuscript, University of Oslo, November. 
Jensen H. (1997), "Monetary Policy Cooperation May Not Be Counterproductive", Scandinavian Journal of Economics, 99, 1, 73-80.

Kydland F. E. and Prescott E. C. (1977), "Rules Rather Than Discretion : The Inconsistency of Optimal Plans", Journal of Political Economy, 85, 473-92.

Lane P. (1999), "Asymmetric Shocks and Monetary Policy in a Currency Union", forthcoming in Scandinavian Journal of Economics.

Lawler P. (2000), "Centralised Wage Setting, Inflation Contracts, and the Optimal Choice of Central Banker", Economic Journal, 110, 559-575.

Lippi F. (1999) "Strategic Monetary Policy with Non-Atomistic Wage Setters: A Case for Non-Neutrality", CEPR DP \#: 2218, August.

Lippi F. (2000) "Revisiting the Case for a Populist Central Banker", Manuscript, Banca d' Italia, March, Forthcoming: European Economic Review.

Nickell S. (1997), "Unemployment and Labor Market Rigidities: Europe versus North America", Journal of Economic Perspectives, 11, No. 3, 55-74.

Nickell S. (1999), "Product Markets and Labour Markets", Labour Economics, 6, 1-20.

OECD (1997), Employment Outlook, July, Paris.

Oswald A.J. (1982), "The Microeconomic Theory of Trade Union", The Economic Journal, 92, 576-595.

Rogoff K. (1985), "The Optimal Degree of Commitment to a Monetary Target", Quarterly Journal of Economics, 100, 1169-1190.

Sibert A. (1999), "Monetary Integration and Economic Reform", The Economic Journal, 109, 78-92, January.

Sibert A. and A. Sutherland (2000), "Monetary Union and Labor Market Reform", Journal of International Economics, 51, 421-435.

Skott P. (1997), "Stagflationary Consequences of Prudent Monetary Policy in a Unionized Economy", Oxford Economic Papers, 49, 609-622.

Soskice D. and T. Iversen (2000), "The Non Neutrality of Monetary Policy with Large Price or Wage Setters", Quarterly Journal of Economics, 115, 265-284. 